\title{
Deep Vein Thrombosis and Pulmonary Embolism in a Mountain Guide: Awareness, Diagnostic Challenges, and Management Considerations at Altitude
}

\author{
Claire M. Hull, PhD; Dévan Rajendran, DO; Arturo Fernandez Barnes, DO \\ From the Swansea University Medical School, Singleton Park, Swansea, Wales, United Kingdom (Dr Hull); the European School of Osteopathy, \\ Research Department, Boxley House, Kent, United Kingdom (Dr Rajendran); and the Centre Thérapeutique Medica, Crans-Montana, \\ Switzerland (Dr Fernandez Barnes).
}

\begin{abstract}
High intensity exercise is associated with several potentially thrombogenic risk factors, including dehydration and hemoconcentration, vascular trauma, musculoskeletal injuries, inflammation, longdistance travel, and contraceptive usage. These are well documented in case reports of venous thrombosis in track and field athletes. For mountaineers and those working at high altitude, additional risks exist. However, despite there being a high degree of vigilance for "classic" conditions encountered at altitude (eg, acute mountain sickness, high altitude pulmonary edema, and high altitude cerebral edema), mainstream awareness regarding thrombotic conditions and their complications in mountain athletes is relatively low. This is significant because thromboembolic events (including deep vein thrombosis, pulmonary embolism, and cerebral vascular thrombosis) are not uncommon at altitude. We describe a case of deep vein thrombosis and pulmonary embolism in a male mountain guide and discuss the diagnostic issues encountered by his medical practitioners. Potential risk factors affecting blood circulation (eg, seated car travel and compression of popliteal vein) and blood hypercoagulability (eg, hypoxia, environmental and psychological stressors [avalanche risk, extreme cold]) relevant to the subject of this report and mountain athletes in general are identified. Considerations for mitigating and managing thrombosis in addition to personalized care planning at altitude are discussed. The prevalence of thrombosis in mountain athletes is uncharted, but lowlanders increasingly go to high altitude to trek, ski, or climb. Blood clots can and do occur in physically active people, and thrombosis prevention and recognition will demand heightened awareness among participants, healthcare practitioners, and the altitude sport/leisure industry at large.
\end{abstract}

Key words: altitude, deep vein thrombosis, exercise, mountain sport, pulmonary embolim, stress

\section{Introduction}

Mountain athletes and those who work or pursue leisure activities at high altitude are exposed to multiple, potentially thrombogenic risk factors (vascular damage, hypercoagulability and circulatory stasis) relating to Virchow's triad (Figure 1). ${ }^{1}$ However, despite there being a high degree of vigilance for "classic" conditions encountered at altitude (eg, acute mountain sickness [AMS], high altitude pulmonary edema, and cerebral edema), mainstream awareness about the risk factors for thrombotic conditions, including deep vein

Corresponding authors: Claire M. Hull, PhD, or Arturo F. Barnes, DO, Swansea University Medicine, Institute of Life Science, Singleton Park, Swansea, Wales SA2 8PP, United Kingdom (e-mail: c.m. hull@swansea.ac.uk or arturofbarnes@gmail.com). thrombosis (DVT) and pulmonary embolism (PE), could be improved. We highlight a case of DVT and PE in an elite male mountain athlete who presented to healthcare practitioners over the course of 1 month and identify his risk factors (Figure 1), "easy to miss" signs and symptoms, and the differential diagnoses that were made before formal diagnosis.

\section{Case Report}

An otherwise healthy 42-year-old male mountain guide (73.8 kg; $178 \mathrm{~cm}$; body mass index 23.29) first presented to medical practitioners at a ski resort $(1000-2000 \mathrm{~m}$ above sea level) with physical fatigue and symptoms typical of a common cold. His heart rate was 60 beats/ min and blood pressure within the normal range (120/80-140/90 $\mathrm{mmHg}$ ). His peripheral capillary oxygen 


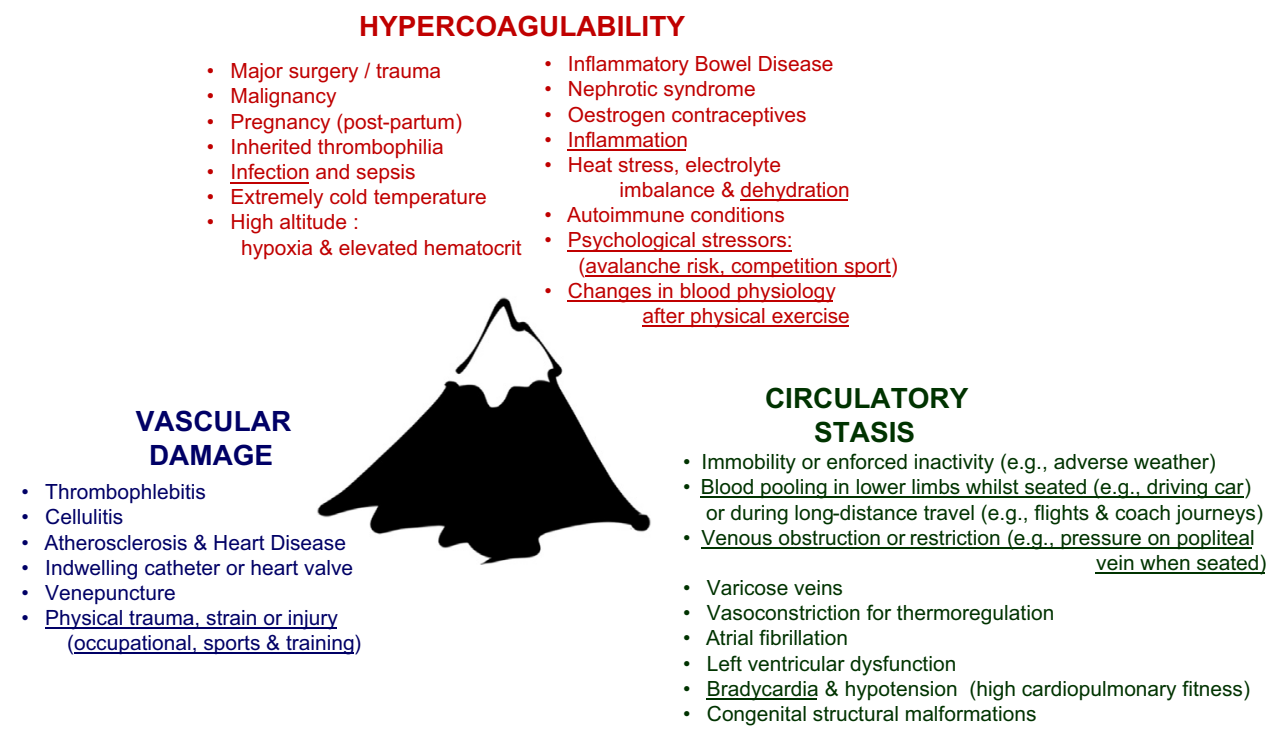

Figure 1. Virchow's triad (circa 1854) for thrombosis and thromboembolic conditions. Risk factors that are believed to have affected the subject of the present study are underlined. Public domain image. ${ }^{1}$

saturation was normal ( $>95 \%)$, and he did not smoke, had no history of lung embolism or thrombosis, and did not experience angina pectoris, edema, or neoplasia. $\mathrm{He}$ was not known to have a hereditary thrombophilia or any other condition related to blood clotting. Auscultation indicated that his lungs were clear bilaterally (normal breath sounds over the dorsal pulmonary fields).

One week after first presentation, the mountain guide presented again after a skiing accident (a minor fall while breaking in new ski boots); he described having strained/ pulled muscle tissue in his left leg but said that he had been continuing to work at high altitude $(\sim 3500 \mathrm{~m})$ as part of an avalanche security team under conditions of extreme cold, psychological stress, and environmental risk (navigating an unmarked track). He commented on breathlessness, general (occupation-related) anxiety, and left calf discomfort that became more apparent when he removed his ski boot. At this point minor swelling (left calf $<2 \mathrm{~cm}$ larger than asymptomatic right calf) was observed and the injury was diagnosed as a muscle tear; the mountain guide was advised to rest.

Five days later the mountain guide again presented to his physician with the same complaints (chronic calf pain and shortness of breath). He commented on feeling physically and psychologically exhausted and stated that he was planning to spend time with his family. Osteopathic articulations of the joints in his lower extremities and back, lymphatic drainage, and massage of the lower extremities were performed. After resting for 2 days after the osteopathic interventions, the mountain guide returned to work (altitudes of 2000-2500 m) for 1 more day before descending (seated car travel for a distance of
$65 \mathrm{~km}$ ) to a lowland area. After his descent from altitude, the mountain guide developed severe thoracic and pleuritic pain, a cough with bloody sputum, and cramp-like sensations in his left shoulder, left vertebral, and lumbar regions. He presented at his doctor's surgery and was immediately referred for a thoracic computed tomography scan, which revealed a paracentral and peripheral pulmonary embolism in the right and left lower lung lobes with infarction pneumonia (groundglass infiltration). He was admitted to the hospital and initiated onto anticoagulation therapy (rivaroxaban) for a minimum of 6 months.

While in the hospital, the mountain guide experienced thoracic pain that worsened upon deep inhalation, hemoptysis, and low-grade fever $\left(37.9^{\circ} \mathrm{C}\right)$. Standard blood profiling (full blood count, liver, renal and electrolytes, blood glucose, hemoglobin) and coagulation screens were unremarkable, but mild homocysteinemia $(19.9 \mu \mathrm{mol} / \mathrm{L})$ was noted. Subsequent tests revealed a raised inflammatory marker (C-reactive protein; $73 \mathrm{mg} / \mathrm{L}$ ) and a significantly elevated D-dimer (ELISA test; $1.7 \mu \mathrm{g} / \mathrm{mL}$ [normal range $0.1-0.5 \mu \mathrm{g} / \mathrm{mL}])$. Follow-up duplex ultrasonography of pelvic and leg veins revealed DVT of the left popliteal vein, left peroneal vein, and tibialis posterior vein. At this time, significant calf pain and calf swelling, often indicative of DVT (Table 1; Wells scoring criteria) were absent. ${ }^{2}$ His heart rate was 90 beats/min, below the Wells score threshold (100 beats/min) for suspected PE (Table 2), and his blood pressure was normal $(128 / 79 \mathrm{mmHg})$. Electrocardiography revealed a normal sinus rhythm and heart rate, unobtrusive de- and repolarisation, and normal conduction time; no signs of right heart strain or abnormal 
Table 1. Wells scoring system for deep venous thrombosis ${ }^{2}$

\begin{tabular}{|c|c|}
\hline Clinical feature & Score \\
\hline $\begin{array}{l}\text { Malignancy (treatment ongoing, within } \\
6 \text { months, or palliative) }\end{array}$ & 1 \\
\hline $\begin{array}{l}\text { Paralysis, paresis, or recent plaster } \\
\text { immobilization of the leg }\end{array}$ & 1 \\
\hline $\begin{array}{l}\text { Recently confined to bed for } \geq 3 \text { days } \\
\text { or major surgery within } 12 \text { weeks } \\
\text { requiring general or regional anesthesia }\end{array}$ & 1 \\
\hline $\begin{array}{l}\text { Localized tenderness along the } \\
\text { distribution of the deep venous system }\end{array}$ & 1 \\
\hline Entire leg swollen & 1 \\
\hline $\begin{array}{l}\text { Calf swelling at least } 3 \mathrm{~cm} \text { larger than } \\
\text { asymptomatic side }\end{array}$ & 1 \\
\hline $\begin{array}{l}\text { Pitting edema confined to the } \\
\text { symptomatic side }\end{array}$ & 1 \\
\hline $\begin{array}{l}\text { Collateral superficial veins } \\
\text { (nonvaricose) }\end{array}$ & 1 \\
\hline $\begin{array}{l}\text { Previously documented deep venous } \\
\text { thrombosis }\end{array}$ & 1 \\
\hline $\begin{array}{l}\text { An alternative diagnosis at least as } \\
\text { likely as deep venous thrombosis }\end{array}$ & \\
\hline
\end{tabular}

Likelihood of deep venous thrombosis: Total score of $\geq 2$ : likely; Total score of $\leq 1$ : unlikely.

heart sounds were apparent. Precautionary transthoracic Doppler echocardiography investigations revealed that the patient's left ventricle was slightly hypertrophied with normal global and regional systolic function (ejection fraction 65\%). This was attributed to his high level of physical fitness and not considered to be of pathological significance.

Table 2. Wells scoring system for pulmonary embolism ${ }^{3}$

\begin{tabular}{lc}
\hline Clinical feature & Score \\
\hline $\begin{array}{l}\text { Clinical signs and symptoms of deep } \\
\text { venous thrombosis (minimum of leg } \\
\text { swelling and pain with palpation of the } \\
\text { deep veins) }\end{array}$ & 3 \\
$\begin{array}{l}\text { An alternative diagnosis that is less } \\
\text { likely than pulmonary embolism }\end{array}$ & 3 \\
$\begin{array}{l}\text { Heart rate > } 100 \text { beats/min } \\
\text { Immobilization for }>3 \text { days or surgery } \\
\begin{array}{l}\text { in the previous } 4 \text { weeks } \\
\text { Previous deep venous thrombosis or } \\
\text { pulmonary embolism }\end{array}\end{array}$ \\
$\begin{array}{l}\text { Haemoptysis } \\
\text { Malignancy (on treatment, treated in the } \\
\text { past } 6 \text { months or palliative) }\end{array}$ & 1.5 \\
\end{tabular}

Likelihood of pulmonary embolism: Total score of $>4$ : likely; Total score of $\leq 4$ : unlikely.
On discharge from hospital, analgesics were prescribed for thoracic pain (Dafalgan [generic name: acetaminophen], Novalgin [generic name: dipyrone]), which diminished completely over time (4 weeks). A follow-up thrombophilia screen (including antiphospholipid syndrome, prothrombin mutation, protein $\mathrm{S}$, protein $\mathrm{C}$, and factor $\mathrm{V}$ Leiden) revealed no abnormalities. In view of the patient's profession (to plan and lead extreme altitude excursions), he was advised to use thigh length Class II compression stockings and to return to activity progressively. The mountain guide returned to work as a teacher and to training (running, cycling, and badminton) within his physical tolerance limits.

This episode was diagnosed as a provoked thromboembolic event. Viral infection, dehydration, and calf muscle injury (and associated inflammation) along with intermittent periods of inactivity (eg, seated car travel to lowland areas) that compressed the popliteal vein and allowed blood to pool in the lower limb were considered to be potential risk factors for circulatory stasis and clot precipitation (Figure 1, underlined factors).

\section{Discussion}

Apart from historical accounts of thrombotic events in Himalayan trekkers documented some 30 years ago, ${ }^{4}$ case reports of high altitude venous thrombosis in athletes and fitness enthusiasts are limited to two climbers ${ }^{5,6}$ an instructor training at simulated high altitude ${ }^{7}$ and a Himalayan mountaineer. ${ }^{8}$ Large-scale hematological studies $^{9-12}$ and more specific accounts of high altitude thrombosis in physically active people have tended to focus on military personnel (eg, cerebral venous thrombosis in serving soldiers ${ }^{13}$ ) and not athletes and/or active people, per se. This is significant because altitude training regimens are often used by lowland competition athletes to improve their sea level performance and because the popularity of high altitude, winter sports, and explorations (eg, the Kilimanjaro Challenge, alpine ascents, and extreme expeditions) continues to grow. Given the potentially lifethreatening consequences of a delayed or missed diagnosis of thrombosis, the need to increase mainstream awareness of the potential risk factors in physically active people at altitude is not trivial.

Case presentations of thrombosis and thromboembolic events in lowland track and field athletes (Hull et $\mathrm{al}^{14}$ and citations therein) highlight the potentially thrombogenic consequences of dehydration and hemoconcentration, vascular trauma, musculoskeletal injuries and inflammation, immobilization during long distance travel (especially after intense event[s]), and contraceptive usage around competitions. Debate has long surrounded how conditions 
at high altitude might contribute to hematological changes (including hypercoagulability) and the establishment of a prothrombotic milieu $^{15}$; however, it is generally accepted ${ }^{16,17}$ that numerous factors could heighten the risk of thrombosis in physically active people who train or work at altitude (Figure 1; Virchow's triad [circa 1854]) ${ }^{1}$ for thrombosis and thromboembolic conditions. These include hypoxia, heat stress and hyperthermia, ${ }^{18}$ extremely low temperature, ${ }^{19}$ and enforced inactivity (which might exacerbate circulatory stasis) because of severe or adverse weather. ${ }^{16-17}$

For the mountaineer in the present case report, studies detailing how changes in blood chemistry that occur after physical activity can lead to a hypercoagulable state are of particular interest. It is currently understood that exercise can induce blood coagulation while simultaneously enhancing blood fibrinolysis (clot breakdown), but that the extent of this equilibrium depends on exercise intensity and duration and the resting fibrinolytic profile of individual people. ${ }^{20}$ Regular sports activities (arguably in relatively acclimatized individuals) appear to decrease the risk of venous thrombosis, and the benefits of moderate exercise are likely to outweigh the risks of no exercise at all for very many people. ${ }^{21}$ However, the risks associated with extremes of exertion in specific patient groups (such as elite athletes and the subject of this report) deserve fuller attention, especially in view of very recent literature that illuminates how high intensity exercise can heighten the risk of thrombotic events. ${ }^{22}$

Of further interest is the literature that describes how hemostatic responses to acute psychosocial stress can result in net hypercoagulability. ${ }^{23-25}$ The potential for chronic stressors, including job strain, to contribute to a chronic low-grade hypercoagulable state have also been identified. ${ }^{26}$ Here, the possibility that a heightened level of psychological stress relating to occupational hazards at altitude (eg, avalanche risk and unpredictable weather) exacerbated or contributed to the mountain guide's condition cannot be discounted. Finally, although his thrombophilia screen was negative, the mountain guide's elevated serum homocysteine $(19.9 \mu \mathrm{mol} / \mathrm{L})$ is noteworthy. The association between hyperhomocysteinemia and thrombosis is generally well recognized. ${ }^{27}$ However, because the actual biochemical mechanisms responsible for this association remain the subject of ongoing debate, the clinical significance of his relatively mild homocysteinemia should be viewed with caution. ${ }^{27}$

Given the cardiopulmonary characteristics (low pulse rate, hypotension, high respiratory efficiency, $\mathrm{VO}_{2} \max$ ) and physical conditioning (muscle tone and low percentage body fat) of many athletic individuals, it has been noted that front-line clinical evaluations (eg, the major Wells scoring criteria) for the most common thrombotic conditions-lower extremity $\mathrm{DVT}^{2}$ (Table 1) and $\mathrm{PE}^{3}$ (Table 2) - may not be readily applicable to athletes ${ }^{14,28}$; the subject of the present report provides a case in point. For example, the mountain guide initially presented with a degree of calf swelling (left calf $<2 \mathrm{~cm}$ larger than asymptomatic right calf) and a heart rate (60 beats/min) that were both below the significance threshold for Wells DVT (Table 1) and PE (Table 2) scoring criteria. Here, the fitness conditioning, physical presentation, and mental stamina of our patient were all factors that may have (1) contributed to and (2) compensated for his symptoms and atypical DVT-PE sequelae. Clinicians and sports physicians should always be mindful of the potential for thrombosis in physically well-conditioned people who may be at greater risk of a missed or delayed diagnosis quite simply because they do not fit the physiological parameters for standard assessment criteria. ${ }^{14,28}$

It is also noteworthy that blood clots can and do occur at numerous anatomical locations. Axillary vein (also termed upper extremity thrombosis ${ }^{29}$ ) and cerebral venous thrombosis $(\mathrm{CVT})^{30}$ warrant specific mention because the physical demand on upper limbs in mountaineers and climbers is often very intense and because case presentations of CVT at altitude have been documented. ${ }^{4,5,7,11,29,30}$ There are no standardized scoring systems for upper extremity thrombosis or CVT, and their diagnoses depends on clinical suspicion and confirmatory imaging techniques (duplex ultrasonography, contrast venography, and magnetic resonance angiography). ${ }^{29,30}$ These diagnostic tools are unavailable in remote, mountainous areas. There is growing interest in the use of portable point-of-care ultrasound for the assessment of sports injuries and/or thrombosis, and it is encouraging to see interest regarding its application at high altitude locations. ${ }^{31}$

Health journaling is not uncommon amongst mountaineers (eg, the Lake Louise Scoring System for AMS) ${ }^{32}$ Here the potential to self-monitor and/or report the signs and symptoms of thrombosis at altitude, perhaps by employing medical aids and questionnaires in addition to the Wells scoring criteria warrants consideration. $^{2,3}$ Basic health journaling and (where possible) physical examination using portable medical aids (eg, tape measure, thermometer, pulse oximeter, peak flow and heart rate monitors) at altitude could assist in the diagnosis of thrombosis/thromboembolic events. In cases of suspected thrombosis, D-dimer determinations using portable kits could inform decisions concerning the provision of emergency responses at altitude, especially because D-dimer testing is already widely employed in clinical practice. ${ }^{33}$ Although the likelihood of obtaining false positives, especially in sports enthusiasts who might be considered as presenting with 
a training injury (eg, muscle tear, sprain, tendon or ligament damage) can be a complicating factor, and although a positive result does not confirm thrombosis, a negative D-dimer practically rules it out. Recent findings from the Mount Everest deep venous thrombosis study concluded that D-dimer levels were not elevated in asymptomatic high altitude climbers. ${ }^{34}$ Given the potential consequences of a "missed-positive" diagnosis of thrombosis, a medical response to a false-positive Ddimer at altitude (where this may be the only practicable diagnostic tool) is defensible.

Of course, athletes and their healthcare professionals should remain mindful that similar symptoms can point toward numerous differential diagnoses (Figure 2). For example, the Lake Louise Scoring System for AMS requires users to grade 5 symptoms (headache, gastrointestinal symptoms, fatigue, dizziness, and difficulty sleeping) on a scale of 0 to 3; the presence of headache plus a total score $\geq 3$ is usually considered positive for $\mathrm{AMS}^{32}$; this score could also indicate the presence of CVT. In the absence of definitive diagnostic information, all cases of serious ill health at altitude should be treated with a high index of suspicion; the risk of thrombosis, even in physically active people, should never be overlooked.
Preventative advice for lowland athletes has highlighted the need to minimize risk of dehydration (and potentially hemoconcentration) that can result from high intensity training $^{35-37}$; mountain athletes are no exception. Given the practical difficulties of carrying, obtaining, and administering sufficient fluid at altitude, mountaineers should make gainful use of opportunities to hydrate themselves. Excessive consumption of caffeinated drinks and alcohol should be avoided, and the possibility of using hydration salts and specialist products that replenish both fluid and electrolytes should be discussed with sports and healthcare professionals. During long journeys, efforts should be made to perform leg and upper body stretches, and the use of compression stockings is advisable. General advice to avoid sitting in cramped positions and crossing legs at the knee and the ankle is also applicable. For altitude athletes who can experience extremes of hot and cold, efforts to keep muscle tissues warm (eg, through layering and warmup/warm-down stretches after intense periods of activity) should not be neglected. Additional measures should be considered and planned with medical practitioners on an individual basis. Taking prophylactic aspirin may be a viable option, but medical advice should always be sought first. ${ }^{38}$

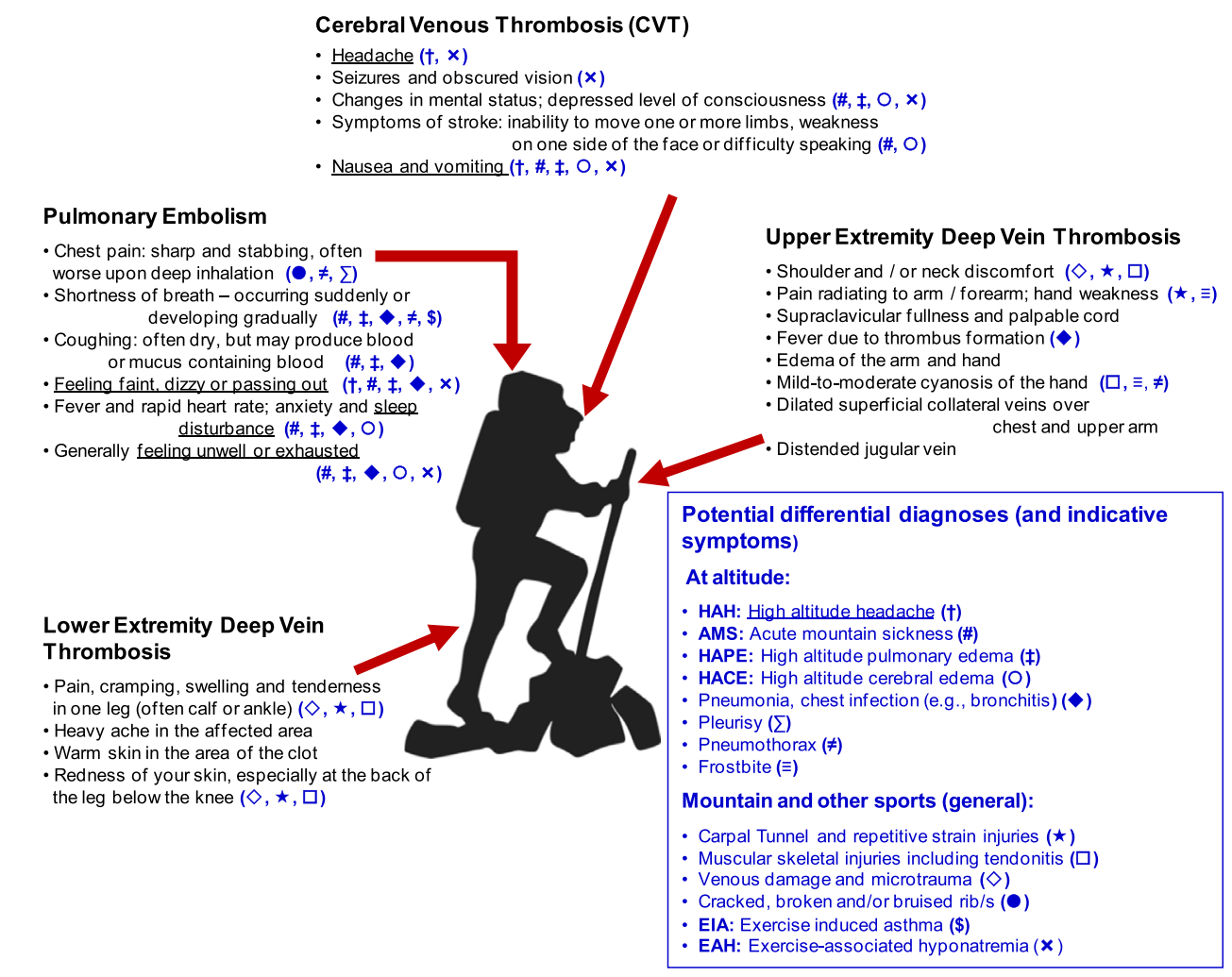

Figure 2. Potential differential diagnoses for venous thrombosis and thromboembolic conditions at altitude and in mountain sportspeople. Underlined symptoms are assessment criteria included in the Lake Louise Scoring System for acute mountain sickness. ${ }^{32}$ Public domain image. 
In the event of any ill-health condition at altitude, mountain athletes must formulate clear emergency care plans and, wherever possible, be evacuated to receive appropriate treatment. ${ }^{39}$ For mountain athletes taking anticoagulant medication, the immediate course of action that should be taken by themselves (and/or those around them) should an accident or injury occur must be clarified. Medical identification bracelets, necessary medical treatment, and contact information in case of emergency should always be carried and the appropriate response to bleeding clearly delineated, especially in patients taking newer anticoagulants (eg, rivaroxaban) for which mainstream antidotes and awareness are less common. For those who wish to continue or pursue altitude sports while taking anticoagulant therapy, emergency care planning will require specific patientpractitioner dialogue, and because of the physical and environmental hazards at high altitude locations, this will likely entail activity and risk concessions on the part of the athlete.

\section{Conclusion}

This case report focuses on the risk factors (Figure 1), differential diagnoses (Figure 2), and clinical assessment criteria (Tables 1 and 2) that prompted the evaluation and final diagnosis of DVT and PE in a male mountain guide. We discuss how and why some mountain athletes could be at heightened risk of a delayed diagnosis given that the signs and symptoms of DVT, PE, and other thromboses (including upper extremity deep vein thrombosis and CVT) can mimic those associated with classic altitude illnesses (eg, AMS, high altitude pulmonary edema, and high altitude cerebral edema) and more general sports-related conditions (eg, exercise-induced asthma, exercise-associated hyonatremia) (Figure 2). The challenge of diagnosing DVT and PE may well be compounded if (as in this account) the physical presentation of an athlete fails to satisfy the significance thresholds of standard assessment criteria (Tables 1 and 2) and especially if a primary index of suspicion toward sports-related injury is maintained. Importantly, scoring systems should never outrank clinical judgment, and it is always prudent to appraise the wider clinical picture, especially when evaluating athletic patients whose training, lifestyle, and physical presentation are often atypical of the adult population at large. ${ }^{14,28}$ Full consideration and diagnostic workup (including D-dimer testing) to exclude (1) DVT in athletes presenting with chronic calf cramp that does not respond to therapeutic interventions (eg, sports massage) or rest from activity, and (2) PE in athletes with unexplained or uncharacteristic shortness of breath (eg, athletes with no history of asthma) are defensible. ${ }^{33}$ Vigilance and awareness about atypical symptomatology and the potential risk factors for thrombosis in mountain athletes are key.

\section{Acknowledgements}

With thanks to Hanna Scholtyssek for translating notes and health documentation and also to the medical team responsible for the care the patient, especially Dr. Nicole Werder (Centramed, Zug) and Dr. Manuel Luhn, Dr. Sibylle Felber, and Dr. T. Braschler (all based at Zuger Kantonsspital AG, Baar).

\section{References}

1. Virchow R. Thrombose und embolie. Gefässentzündung und septische infektion. In: Gesammelte Abhandlungen zur wissenschaftlichen Medicin [in German]. Translation in Matzdorff AC, Bell WR. Thrombosis and Embolie (18461856). Canton, MA: Science History Publications; 1998.

2. Wells PS, Anderson DR, Rodger M, et al. Evaluation of D-dimer in the diagnosis of suspected deep-vein thrombosis. N Engl J Med. 2003;349:1227-1235.

3. Wells PS, Anderson DR, Rodger M, et al. Derivation of a simple clinical model to categorize patients probability of pulmonary embolism: increasing the models utility with the SimpliRED D-dimer. Thromb Haemost. 2000;83: 416-420.

4. Dickinson J, Heath D, Gosney J, Williams D. Altituderelated deaths in seven trekkers in the Himalayas. Thorax. 1983;38:646-656.

5. Boulos P, Kouroukis C, Blake G. Superior sagittal sinus thrombosis occurring at high altitude associated with protein C deficiency. Acta Haematol. 2000;102:104-106.

6. Cheng S, Chng SM, Singh R. Cerebral venous infarction during a high altitude expedition. Singapore Med J. 2009;50:e306-e308.

7. Torgovicky R, Azaria B, Grossman A, Eliyahu U, Goldstein L. Sinus vein thrombosis following exposure to simulated high altitude. Aviat Space Environ Med. 2005;76: 144-146.

8. Prabhakar A, Aggarwal M, Khurana P, Trehan N. Rare case of cerebral stroke and venous thrombosis developed during high altitude expedition. Indian J Radiol Imaging. 2006;16:313-314.

9. Anand AC, Saha A, Seth AK, Chopra GS, Nair V, Sharma V. Symptomatic portal system thrombosis in soldiers due to extended stay at extreme altitude. J Gastroenterol Hepatol. 2005;20:777-783.

10. Khalil KF, Saeed W. Pulmonary embolism in soldiers serving at high altitude. J Coll Physicians Surg Pak. 2010;20:468-471.

11. Kumar S. High altitude induced deep venous thrombosis: a study of 28 cases. Indian J Surg. 2006;68:84-88.

12. Wheatley K, Creed M, Mellor A. Haematological changes at altitude. J R Army Med Corps. 2011;157:38-42. 
13. Jha SK, Anand AC, Sharma V, Kumar N, Adya CM. Stroke at high altitude: Indian experience. High Alt Med Biol. 2002;3:21-27.

14. Hull CM, Hopkins CL, Purdy NJ, Lloyd RC, Harris JA. A case of unprovoked venous thromboembolism in a marathon athlete presenting atypical sequelae: what are the chances? Scand J Med Sci Sports. 2015;25:699-705.

15. Gupta N, Ashraf MZ. Exposure to high altitude: a risk factor for venous thromboembolism? Semin Thromb Hemost. 2012;38:156-163.

16. Grissom CK. Respiratory disorders. In: Wilkerson JA, Moore EE, Zafren K, eds. Medicine for Mountaineering and Other Wilderness Activities. 6th ed. Seattle, WA: Mountaineers Books; 2010:169-178.

17. West JB, Schoene RB, Milledge JS. High Altitude Medicine and Physiology. 4th ed. London, UK: Hodder Arnold; 2007.

18. Simon HB. Hyperthermia. N Engl J Med. 1993;329: 483-487.

19. Nagelkirk PR, Hogan KB, Hoare JM. Ambient temperature affects thrombotic potential at rest and following exercise. Thromb Res. 2012;130:248-252.

20. El-Sayed MS, El-Sayed Ali Z, Ahmadizad S. Exercise and training effects on blood haemostasis in health and disease: an update. Sports Med. 2004;34:181-200.

21. van Stralen KJ, Le Cessie S, Rosendaal FR, et al. Regular sports activities decrease the risk of venous thrombosis. J Thromb Haemost. 2007;5:2186-2192.

22. Posthuma JJ, van der Meijden PE, Ten Cate H, et al. Short- and Long-term exercise induced alterations in haemostasis: a review of the literature. Blood Rev. 2015;29:171-178.

23. Thrall G, Lane D, Carroll D, et al. A systematic review of the effects of acute psychological stress and physical activity on haemorheology, coagulation, fibrinolysis and platelet reactivity: implications for the pathogenesis of acute coronary syndromes. Thromb Res. 2007;120:819-847.

24. von Känel R, Hepp U, Buddeberg C, et al. Altered blood coagulation in patients with posttraumatic stress disorder. Psychosom Med. 2006;68:598-604.

25. von Känel R, Mills PJ, Fainman C, et al. Effects of psychological stress and psychiatric disorders on blood coagulation and fibrinolysis: a biobehavioral pathway to coronary artery disease? Psychosom Med. 2001;63:531-544.
26. Austin AW, Wissmann T, von Känel R. Stress and hemostasis: an update. Semin Thromb Hemost. 2013;39: 902-912.

27. Fay WP. Homocysteine and thrombosis: guilt by association? Blood. 2012;29(119):2977-2978.

28. Hull CM, Harris JA. Venous thromboembolism in physically active people: considerations for risk assessment, mainstream awareness and future research. Sports Med. 2015;45:1365-1372.

29. Joffe HV, Goldhaber SZ. Upper-extremity deep vein thrombosis. Circulation. 2002;106:1874-1880.

30. Saposnik G, Barinagarrementeria F, Brown RD Jr, et al. Diagnosis and management of cerebral venous thrombosis: a statement for healthcare professionals from the American Heart Association/American Stroke Association. Stroke. 2011;42:1158-1192.

31. Evans CS, Harris NS. Ultrasound and ski resort clinics: mapping out the potential benefits. Wilderness Environ Med. 2012;23:239-247.

32. Roach RC, Bärtsch P, Oelz O, Hackett PH. The Lake Louise acute mountain sickness scoring system. In: Sutton JR, Houston CS, Coates G, eds. Hypoxia and Molecular Medicine Burlington, VT: Queen City Press; 1993:272-274.

33. Bockenstedt P. D-dimer in venous thromboembolism. N Engl J Med. 2003;349:1203-1204.

34. Zafren K, Feldman J, Becker RJ, Williams SR, Weiss EA, Deloughery T. D-dimer is not elevated in asymptomatic high altitude climbers after descent to $5340 \mathrm{~m}$ : the Mount Everest Deep Venous Thrombosis Study (Ev-DVT). High Alt Med Biol. 2011;12:223-227.

35. Grabowski G, Whiteside WK, Kanwisher M. Venous thrombosis in athletes. $J$ Am Acad Orthop Surg. 2013;21:108-117.

36. Hull CM, Harris JA. Venous thromboembolism: awareness information for marathon athletes. Circulation. 2013;128: e469-e471.

37. Meyering C, Howard T. Hypercoagulability in athletes. Curr Sports Med Rep. 2004;3:77-83.

38. Becattini C, Agnelli G, Schenone A, et al. Aspirin for preventing the recurrence of venous thromboembolism. $N$ Engl J Med. 2012;366:1959-1967.

39. Taylor AT. High-altitude illnesses: physiology, risk factors, prevention, and treatment. Rambam Maimonides Med J. 2011;31(2):e0022. 